\title{
APLIKASI PENGOLAHAN DATA SPBU ( STASIUN PENGISIAN BAHAN BAKAR UMUM ) PT. SINAR MUSTIKA BINTAN KM 19 BINTAN TIMUR
}

\author{
Elvianna $^{1}$, Nurul Saepul ${ }^{2}$, Doni Kristianto ${ }^{3 *}$ \\ 1,22,3 Jurusan Teknik Informatika STT Indonesia Tanjungpinang \\ Jln. Poma Air No. 28 Tanjungpinang Kepulauan Riau Indonesia \\ 1'elvianna@sttindonesia.ac.id \\ ${ }^{2}$ saepul@sttindonesia.ac.id \\ 3 donikisrantoputra@gmail.com
}

\begin{abstract}
Intisari- Laporan skripsi ini disusun berdasarkan hasil analisa terhadap sistem pendataan yang sedang berjalan serta hasil perancangan sistem baru di PT. SINAR MUSTIKA BINTAN SPBU Km 19 Bintan Timur. Hasil analisa menunjukkan bahwa pengolahan data secara manual menimbulkan beberapa permasalahan sehingga kinerja sistem menjadi kurang efisien.

Untuk memperbaiki kekurangan-kekurangan yang ada pada sistem yang sedang diterapkan, sebuah sistem baru dirancang agar dapat meningkatkan efisiensi kerja. Aplikasi Pengolahan Data yang dikembangkan dapat membantu dalam menyelesaikan permasalahan yang ada sebelumnya. Aplikasi ini dibangun dengan menggunakan Borland Delphi 7.0. Dengan adanya sistem dan aplikasi yang baru ini, diharapkan agar proses kerja akan lebih efisien dan dapat mengalami peningkatan. Kata kunci- Aplikasi, pendataan, desktop
\end{abstract}

Abstract - This thesis report is prepared based on the results of the analysis of the ongoing data collection system as well as the results of designing a new system at PT. SINAR MUSTIKA BINTAN SPBU Km 19 East Bintan. The results of the analysis show that manual data processing causes several problems so that the system performance becomes less efficient.

To fix the deficiencies that exist in the system that is being implemented, a new system is designed to increase work efficiency. The data processing application developed can help solve problems that have existed before. This application was built using Borland Delphi 7.0. With this new system and application, it is hoped that the work process will be more efficient and can be improved. Keywords-Applications, data collection, desktop

\section{Pendahuluan}

\section{A. Pendahuluan}

SPBU (Stasiun Pengisian Bahan Bakar untuk Umum) merupakan prasarana umum yang disediakan oleh PT. Pertamina untuk masyarakat luas guna memenuhi kebutuhan bahan bakar. Pada umumnya SPBU menjual bahan bakar sejenis premium, pertalite, solar dan dexlite. Dengan semakin berkembangnya teknologi informasi yang setiap hari makin meningkat, secara tidak langsung menuntut setiap perusahaan untuk mampu melakukan pembenahan dan peningkatan efektivitas dalam kinerja dengan memanfaatkan sumber daya manusia yang handal dan teknologi sistem informasi yang tepat dan efektif. ${ }^{(1)}$

Saat ini pada kenyataannya setiap pekerjaan apapun yang berhubungan langsung dengan sistem pengolahan data dilakukan dengan menggunakan bantuan komputer dengan tujuan untuk menghindari dan meminimalkan kesalahankesalahan yang mungkin terjadi serta mempertinggi tingkat keakuratan dalam proses pengolahan data sehingga dapat memberikan suatu sistem informasi yang dibutuhkan secara tepat, lengkap, akurat dan cepat. Sistem informasi merupakan kombinasi teratur apapun dari orang-orang, hardware, software, jaringan komunikasi, dan sumber daya data yang mengumpulkannya, mengubah, dan menyebarkan informasi dalam sebuah organisasi, maka dari itu untuk menunjang dan mempermudah suatu kinerja yang efektif dan efisien perusahaan sangat membutuhkan suatu perangkat keras (Hardware) dan juga perangkat lunak (Software) yang dapat menangani langsung dalam proses pengolahan data tersebut sehingga pekerjaan yang sesulit apapun akan terasa lebih efektif dan efisisen. ${ }^{(2)}$

PT. Sinar Mustika Bintan SPBU Km 19 Bintan Timur selama ini masih menggunakan sistem microsoft excel dalam mengolah data. Pada awalnya sistem microsoft excel tersebut masih dapat ditangani oleh PT. Sinar Mustika Bintan SPBU Km 19 Bintan Timur dengan baik dan tidak mengalami kesulitan yang cukup berarti.

Seiring dengan perkembangan yang telah terjadi dan dengan bertambah banyaknya pengolahan data seperti perhitungan liter pershift/perhari bahan bakar, pendapatan cash pershift/perhari, pembelian bahan bakar, oli, tabung lpg, gaji karyawan dan lain-lainnya di PT. Sinar Mustika Bintan SPBU Km 19 Bintan Timur yang terdata. Maka pengolahan data yang lebih efektif dan efisien bagi SPBU Km 19 Bintan 
Timur sangat diperlukan, dan mulai jadi masalah bagi PT. Sinar Mustika Bintan SPBU Km 19 Bintan Timur dalam proses pendataan yang banyak maupun pencarian data dari folder ke folder lainnya.

Permasalahan tersebut membuat pihak PT. Sinar Mustika Bintan SPBU Km 19 Bintan Timur merasa perlu untuk mengkomputerisasi data-data yang ada, karena sistem yang dilakukan dengan microsoft excel banyak memakan waktu, banyaknya data dan memerlukan proses yang panjang serta memakan waktu yang cukup lama, dan sering sekali mengalami kesalahan-kesalahan dalam pencarian data. Maka penyelesaiannya adalah dengan pembuatan Aplikasi Pengolahan Data.

\section{LANDASAN TEORI}

\section{A. Sejarah Singkat SPBU yang Berstatus Pasti Pas}

SPBU yang pertama kali mempunyai status Pasti Pas adalah PT. Sinar Mustika Bintan yang terletak di kijang, Bintan Timur. PT. Sinar Mustika Bintan ini didirikan oleh bapak Haji Muchtar Hasan selaku owner yang mempunyai dua SPBU bertempat di Jl. Toapaya km 16 Bintan Gunung kijang. Pada tahun 09-februari-2015 perusahaan ini membuka cabang di Jl. Nusantara km 19 kecamatan bintan timur. Perusahaan ini bergerak dibidang penjualan bahan bakar, seperti premium, pertalite, solar, dexlite, oli dan tabung lpg dengan berbagai ukuran.

Pembukaan PT. Sinar Mustika Bintan ini sangat membantu masyarakat dalam hal pengisian bahan bakar sehari-hari. Seperti kendaraan mobil, motor, oli dan untuk kebutuhan dapur ibu rumah tangga yaitu tabung lpg dengan berbagai ukuran. PT. Sinar Mustika Bintan ini berstatus "PASTI PAS" dari PT. Pertamina (Persero).

Arti dari slogan "PASTI PAS" adalah kualitas bahan bakar dan takaran pada bahan bakar, setiap SPBU "PASTI PAS" dilengkapi dengan mesin tera ukuran 10 liter atau 20 liter yang merupakan alat untuk menstandarisasi pengukuran dari Dinas Metrologi serta sebagai alat untuk pengecekan ketetapan. Selain itu, konsumen juga berhak mengajukan uji kualitas/dentitas yang merupakan pengujian BBM untuk memastikan kesesuaian masa jenis dan suhu jenis bahan bakar yang disimpan dan dijual di SPBU tersebut.

PT. Sinar Mustika Bintan juga membantu dalam hal rekrut pekerja yang dimana pekerja 50\% diambil dari domisili atau masyarakat sekitar tempat bernaungnya perusahaan tersebut.

Visi dan Misi

1) Visi

a. Menjadi Perusahaan yag handal dalam pekerjaan dan prima dalam pelayanan.

2) Misi

b. Menjadi SPBU yang berkualitas.

a. Memberikan kemudahan kepada masyarakat untuk mengisi BBM.

b. Memberikan kenyamanan pelayanan kepada konsumen dalam membeli BBM dengan slogan "PASTI PAS".

\section{B. Pengertian Penjualan}

Dibawah ini akan dijelaskan secara jelas dan tegas dari pengertian penjualan menurut beberapa ahli yaitu sebagai berikut :

1) Menurut Moekijat dalam buku "Kamus Istilah Ekonomi" bahwa penjualan adalah suatu kegiatan yang ditujukan untuk mencari pembeli, mempengaruhi dan memberikan petunjuk agar pembeli dapat menyesuaikan kebutuhannya dengan produk yang ditawarkan serta mengadakan perjanjian mengenai harga yang menguntungkan bagi kedua belah pihak.

2) Menurut Philip Kotler yang diterjemahkan oleh Ronny A. Rusli dan Hendra dalam buku "Manajemen Pemasaran" bahwa penjualan adalah proses sosial manajerial dimana individu dan kelompok mendapatkan apa yang mereka butuhkan dan ingingkan, menciptakan, menawarkan dan mempertukarkan produk yang bernilai dengan pihak lain.

3) Menurut Kusnadi dalam buku "Akuntansi Keuangan" bahwa penjualan adalah sejumlah uang yang dibebankan kepada pembeli atas barang dan jasa yang dijual. Dari beberapa pengertian penjualan yang telah diterangkan diatas maka dapat disimpulkan bahwa penjualan adalah kegiatan yang terpadu untuk mengembangkan rencana-rencana strategis yang diarahkan kepada usaha pemuasan kebutuhan serta keinginan pembeli/ konsumen, guna untuk mendapatkan penjualan yang menghasilkan laba atau keuntungan.

\section{Penggajian}

Gaji adalah suatu bentuk balas jasa ataupun penghargaan yang diberikan secara teratur kepada seorang atas jasa dan hasil kerjanya. Gaji sering juga disebut sebagai upah, dimana keduanya merupakan suatu bentuk kompensasi. Perbedaan gaji dan upah hanya terletak pada kuatnya ikatan kontrak kerja dan jangka waktu penerimaannya. Seorang menerima gaji pada umumnya diberikan pada setiap akhir bulan dan jumlahnya tetap (Haryono, 2003 dalam Rahayu, 2012). ${ }^{(3)}$

Menurut Sembiring (2008:23) menambahkan bahwa setiap karyawan berhak atas imbalan (remunerasi) sebagai imbalan jasa atas pekerjaan yang dilakukan perusahaan. Atas jasa yang telah dilakukan oleh karyawan perusahaan memberikan imbalan yang biasanya berupa gaji atau upah. Karena gaji merupakan unsur yang penting bagi perusahaan, maka diperlukan suatu sistem yang dapat mengelola gaji secara baik. Sistem penggajian merupakan suatu jaringan prosedur yang dibuat secara terpadu untuk menghasilkan informasi mengenai gaji pegawai secara akurat dan memadai sehingga informasi tersebut dapat berguna bagi piha-pihak yang memerlukan. ${ }^{(4)}$

\section{Metodologi Penelitian}

Metodelogi penelitian yang dibuat terdiri dari beberapa langkah, yaitu: 


\section{A. Metode Pengumpulan data}

Penelitian ini menggunakan beberapa metode pengumpulan data, diantaranya :

1) Observasi

Mengamati secara langsung proses pendataan yang dilaksanakan di PT. Sinar Mustika Bintan SPBU Km 19 Bintan Timur untuk memperoleh gambaran yang jelas mengenai objek yang diteliti.

2) Wawancara (Interview)

Melakukan dialog (Tanya Jawab) secara langsung dengan bagian Direktur, Admin dan Pengawas di PT. Sinar Mustika Bintan SPBU Km 19 Bintan Timur dalam memberikan keterangan terhadap data yang dibutuhkan.

3) Studi Pustaka

Studi pustaka dilakukan untuk pengumpulan data secara tidak langsung dengan melakukan studi kepustakaan yaitu mengumpulkan data-data dan teori-teori yang berhubungan dengan penulisan laporan tugas akhir ini.

\section{B. Metode Pengembangan Perangkat Lunak}

Metode pengembangan sistem yang digunakan adalah pendekatan terstruktur atau waterfall yang terdiri dari beberapa tahap kegiatan yaitu :

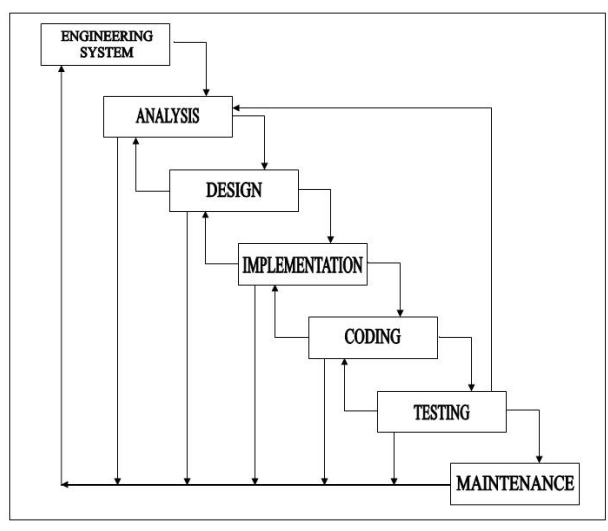

Gambar 1 Paradigma Waterfall

\section{Keterangan :}

1) Engineering System (Perencanaan) adalah Tahapan mengenai masalah perangkat lunak, perangkat keras dan sumber daya manusia.

2) Analysis (Analisis) adalah Melakukan analisis sistem dengan mencari penyebab - penyebab masalah yang timbul sebagai dasar perancangan sistem baru.

3) Design (Perancangan) adalah Proses mengubah kebutuhan - kebutuhan menjadi bentuk karateristik yang dimulai dengan penulisan program design tadi harus diubah menjadi bentuk yang dimengerti sistem.

4) Implementation (Implementasi) adalah Tahap penerjemahan desain kedalam bahasa pemograman yang sesuai dengan kebutuhan.

5) Coding (Pengkodean) adalah desain yang harus diubah bentuknya menjadi bentuk yang dimengerti oleh komputer. Tahapan ini yang secara teknik akan dikerjakan oleh pelaku sistem.
6) Testing (Pengujian) adalah Tahap pengujian perangkat lunak yang telah dikembangkan untuk mengcover kesalah - kesalahan dan menjamin bahwa masukan sesuai dengan hasil yang dibutuhkan.

7) Maintenance (Pemeliharaan) adalah Tahap perawatan sistem yang telah dikembangkan seperti perawatan perangkat lunak, perangkat keras dan media lain yang berhubungan dengan komputer. Pada tahap ini segala kemungkinan mengenai kekurangan perangkat lunak baik berupa kesalahan atau hal - hal yang ditambahkan kedalam perangkat lunak.

\section{HASIL DAN PENELITIAN}

\section{A. Analisis Kelemahan Sistem}

Dari hasil observasi terhadap proses pengolahan data penjualan yang sedang berjalan dilakukan secara manual pada PT. Sinar Mustika Bintan SPBU Km 19 Bintan Timur dianggap kurang efektif serta tidak efisien. ${ }^{(9)}$ Berikut adalah kelemahan dari sistem, diantaranya :

1) Di dalam mengolah database, hak akses user masih belum jelas sehingga data user bisa dimanipulasi oleh user lain.

2) Belum adanya orang yang berperan sebagai Administrator sehingga tidak ada orang yang dapat menjaga dan memelihara sistem yang sedang berjalan, termasuk pengaturan hak akses. Solusi yang diusulkan yaitu dilakukan pembuatan hak akses yang jelas untuk tiap-tiap user dengan menerapkan password untuk user, sehingga user tidak dapat sembarangan dalam pengolahan data.

3) Program yang di gunakan masih menggunakan microsoft excel, yang dimana banyak sekali data-data yang sulit untuk di cari, sehingga dinilai kurang efektif dan efisien.

4) User membuka data perhari biasanya membuka sampai empat atau lima data Microsoft excel, seperti penjualan bahan bakar, pembelian bahan bakar, oli, tabung lpg, gaji karyawan dll.

\section{B. Perancangan Sistem}

Perancangan proses merupakan proses usulan sebagai perbaikan dari proses yang sedang berjalan. Perancangan proses akan ditampilkan dalam bentuk diagram-diagram seperti flowchart, flowmap, diagram konteks, dan DFD. ${ }^{(5)}$

a) Prosedur pendataan penjualan yang diusulkan

1) Operator pershift mencatat dan mengecek hasil penjualan SPBU saat pergantian shift atau jam pulang kerja shift dan diberikan kepada Admin.

2) Operator mencatat data bahan bakar, seperti jumlah liter penjualan bahan bakar pershift, penjualan Oli dan penjualan tabung LPG menurut hasil penjualan pershift. Dihitung dan diperiksa untuk di laporkan atau di data lebih lanjut oleh Admin.

3) Oleh Admin akan mengecek hasil penjualan pershift. Apabila data penjualan tidak benar, data penjualan akan dikembalikan kepada Operator untuk dicek kembali. Apabila data 
lengkap dan benar, data penjualan selanjutnya akan melakukan input data penjualan.

4) Admin PT. Sinar Mustika Bintan SPBU Km 19 Bintan Timur mencetak laporan data penjualan sebanyak dua rangkap. Yang akan diserahkan kepada Direktur dan Direktur Utama.

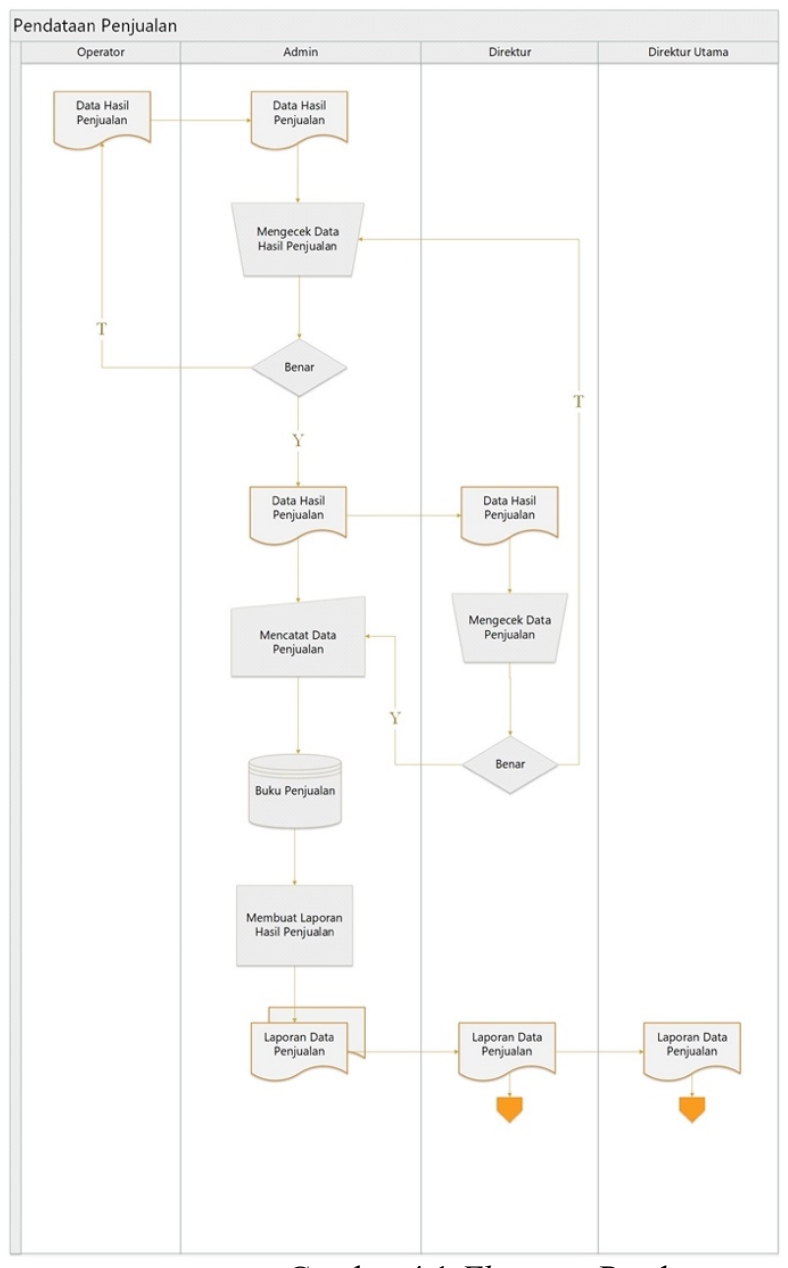

Gambar 4.1 Flowmap Pendataan

Penjualan

b. Prosedur Data Gaji Karyawan yang diusulkan

1)Karyawan melakukan absensi setiap hari ketika datang dan pulang kerja dan diberikan kepada Admin.

2)Karyawan mengisi form absensi yang sudah disediakan oleh Admin untuk di laporkan atau di data lebih lanjut oleh Admin.

3)Oleh Admin di cek form absensi sesuai dengan kehadiran karyawan perhari nya, jika tidak benar form absensi akan dikembalikan kepada karyawan, jika benar form absensi akan dicek dan diinput dengan ketentuan yang berlaku, seperti extra off, extra time, bonus pasti pas, pinjaman dan kurang setor. Oleh Admin akan di input pada data gaji karyawan dan diberikan pada perbulannya kepada Direktur laporan data gaji karyawan perbulannya.
4)Oleh Direktur data laporan gaji karyawan di cek. Apabila tidak benar, laporan data gaji karyawan akan dikembalikan kepada Admin. Jika data benar, laporan data gaji karyawan diarsipkan kepada direktur dan direktur utama, selanjutnya Admin akan mencetak slip gaji perbulannya. Admin memberikan slip gaji kepada karyawan dan ditanda tangani lalu diarsipkan untuk karyawan dan untuk Admin.

\section{Diagram Konteks}

Diagram konteks menggambarkan ruang lingkup sistem secara global. Diagram ini menggambarkan hubungan antara sistem dengan entitas external. ${ }^{(6)}$

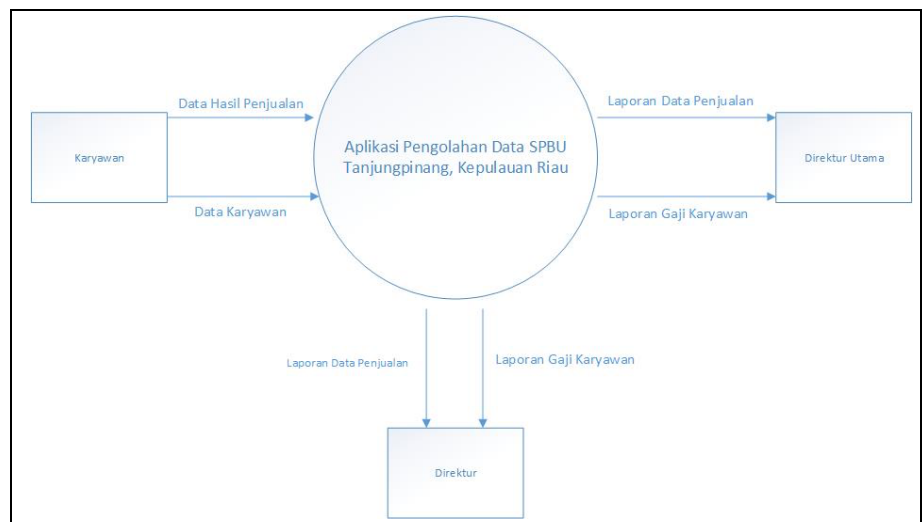

Gambar 4.3 Diagram Konteks

\section{Data Flow Diagram}

Data Flow Diagram (DFD) digunakan untuk menggambarkan arus data dalam sistem secara logika, tanpa mempertimbangkan lingkungan fisik dimana data tersebut akan disimpan. ${ }^{(7)}$

Data Flow Diagram (DFD) memperlihatkan aliran data secara terstruktur. Dalam DFD, data input dan output digambarkan sesuai dengan setiap proses dalam sistem. Untuk menjelaskan setiap proses beserta input dan output, DFD dibagi menjadi beberapa tingkatan agar penjelasan dapat dilakukan secara terperinci. ${ }^{(8)}$

\section{Kesimpulan}

Kesimpulan dari proses kerja praktek serta pembuatan Aplikasi Pengolahan Data SPBU ( Stasiun Pengisian Bahan Bakar Umum ) PT. Sinar Mustika Bintan SPBU Km 19 Bintan Timur adalah :

1) Penyimpanan dan pemrosesan data secara komputerisasi dapat mengurangi kesalahan yang sering terjadi dalam proses pendataan.

2) Waktu yang dihasilkan dengan terkomputerisasi akan lebih efisien, contohnya pada pencarian data, aplikasi ini dapat melakukan pencrian data berdasarkan tanggal, bulan dan tahun.

3) Aplikasi ini memiliki sistem login yang dimana login ini diperlukan username, password dan level sesuai pekerjaan yang ditempati diperusahaan tersebut, dan masing-masing level memiliki hak akses yang berbeda-beda. 
Aplikasi yang telah dibuat dapat membantu dalam pencarian data, membuat laporan sesuai kegiatan yang dilakukan.

Berikut adalah saran dari penyusun kepada pengguna mengenai aplikasi yang telah dibuat :

a) Aplikasi hendaknya terus dievaluasi dan dikembangkan sesuai dengan kebutuhan pihak Perusahaan SPBU PT. Sinar Mustika Bintan SPBU Km 19 Bintan Timur.

b) Disarankan agar aplikasi dipelihara secara berkala.

c) Pengguna hendaknya memperhatikan kekurangan dari aplikasi yang telah dibuat agar aplikasi dapat segera diperbaiki.

\section{REFERENSI}

[1] Supono. Vidiandry,P. 2016. 'Pemograman Web Menggunakan PHP dan Framework Codeigniter'. -Ed. 1(1). Yogyakarta : Deepublish.
[2] Roy,RW. Noor,I. Achmad,J. 2009. 'Perancangan Dan Pengembangan sistem Pelaporan Terpadu Sistem Informasi Puskesmas (SPT SIMPUS) Dengan Metode BPR'. Jurnal Ilmiah Kursor Menuju Solusi Teknologi Informasi. vol 5. No 2.

[3] Danang,J. Qorinta,S. Fitro,N. 2013. 'Perancangan Sistem Informasi Pelaporan Monografi Berbasis Web (Studi Kasus Pada Kantor Kecamatan Semarang Utara)'. Jurnal Speed - Sentra penelitian Engineering dan Edukasi. vol 5. No 2.

[4] Eka,W,H. 2011. 'Penerapan Pola Hierachical Model-View-Controller Pada Rekayasa Sistem Berbasis Web Framework'. Jurnal Teknologi Technoscientia, $\mathrm{v}$ ol 3. No 2.

[5] Eka,W,H. 2011. 'Penerapan Pola Hierachical Model-View-Controller Pada Rekayasa Sistem Berbasis Web Framework'. Jurnal Teknologi Technoscientia, $v$ ol 3. No 2.

[6] Peraturan Walikota Salatiga, 2016, 'Tugas Dan Fungsi Serta Tata Kerja Dinas Perdagangan', Salatiga, Dinas Perdangangan..

[7] Haryono, Rahayu. 2003.Kinerja Dalam Penggajian. Sekolah Tinggi Ilmu Ekonomi YKPN. Yogyakarta.

[8] Dr. Sentosa Sembiring, S.H., M.H, Hukum Perusahaan, Nuansa Aulia, Bandung, 2008:23.

[9] Adi Nugroho, Analisis dan Perancangan Sistem Informasi Dengan Metodologi Berorientasi Objek, Informatika, Bandung, 2005. 